https://artnodes.uoc.edu

\title{
Making touch visible with the suture of fantasy with virtual aesthetician in "The Best Facial Clinic" - The glitchy-score of tele-synaesthesia performance in the age of global pandemic
}

\author{
Ada Xiaoyu Hao \\ University of Brighton \\ Date of submission: May 2021 \\ Accepted in: May 2021 \\ Published in: July 2021
}

\section{Recommended citation}

Hao, Ada Xiaoyu. 2021. «Making touch visible with the suture of fantasy with virtual aesthetician in "The Best Facial Clinic" - The glitchy-score of tele-synaesthesia performance in the age of global pandemic». In: González Díaz, Paloma; García Méndez, Andrea (coord.) «In the limits of what is possible: art, science and technology». Artnodes, no. 28: 1-13. UOC. [Accessed: dd/mm/yy]. http://doi.org/10.7238/a.v0i28.387149

\footnotetext{
Abstract

In the wake of the COVID-19 pandemic, we have been adapting as fugitives of this accidental encounter with an "untouchable" virus, while being rendered into the shared virtual arena, where our discursive bodies are situated within, embedded in and tele-commuted to. Our increasing dependence on online interaction and video conferencing during the pandemic is not only facilitating social connectedness, but also contemplating the question: How to elongate our somatosensation and echo the embodied experience of touching through the incorporeal virtual connectivity? This essay focuses on the embodied nature of tele-synaesthesia performance,
} 


\section{artnodes}

https://artnodes.uoc.edu

Making touch visible with the suture of fantasy with virtual aesthetician in

"The Best Facial Clinic" - The glitchy-score of tele-synaesthesia perfor-mance in the age of global pandemic

its potential effect of forging a rhythmic connection from one sensuous modality to another, and the concurrent emergences of glitch and internet latency as non-verbal cues of internet-situated communication. In reference to Laura Mark's theory of haptic visuality, where vision triggers a tactile experience in the body; Naomi Bennett's concept of virtual touch, in which an affective sensory response of touch can be elicited through non-tactile senses, Paul Sermon's artistic production of Telematic Quarantine (2020) and Pandemic Encounter (2020), that telepresents the stories of self (isolation), and in relation to Michel Foucault's concept Heterotopia in the context of internet-situated performance, I examine the performance work I have been developing during lockdown since March 2020: The Best Facial (2021), supported by Centre for Digital Media Cultures Research and School of Art Postgraduate Research at University of Brighton, a number of sessions of 25-minute 1-to-1 participatory tele-synaesthesia performances that take place on Zoom, where I become a virtual aesthetician and use telepresence to perform meditative virtual facial tactics, and to make tele-contact improvisation upon the surface of the participant's face to trigger tactile experiences through haptic visuality, virtual touching, and auditory fantasization.

\section{Keywords}

Participatory performance, Haptic visuality, Heterotopia, Telecommunication, Synaesthesia, Glitch

Hacer «visible» el tacto mediante la unión de la fantasía con la esteticista virtual en The Best Facial Clinic: el índice de fallos técnicos en la telesinestesia en época de pandemia mundial

\section{Resumen}

A raíz de la pandemia de la COVID-19, nos hemos ido adaptando como fugitivos de esta lucha contra el virus «intocable» a la vez que se vuelve un escenario virtual compartido, donde nuestros cuerpos prolijos se encuentran dentro, incrustados y teletrabajando. Nuestra creciente dependencia de la interacción en línea y de las videoconferencias durante la pandemia no solo facilitan la conexión social, sino que también nos hace considerar lo siguiente: ¿Cómo prolongar nuestra sensibilidad somática y hacernos eco de la experiencia corporal de tocar a través de la conectividad virtual incorpórea? En este ensayo me centro en la naturaleza encarnada de la interpretación de la telesinestesia, su efecto potencial de forjar una conexión rítmica de una modalidad sensorial a otra, y la aparición de fallos técnicos y la latencia de Internet como indicios no verbales de la comunicación a través Internet. En referencia a la teoría de la «visualidad háptica» de Laura Mark, en que la visión desencadena una experiencia táctil en el cuerpo; al concepto "tacto virtual» de Naomi Bennett, con el que se puede provocar una respuesta sensorial afectiva del tacto a través de sentidos no táctiles; a las producciones artísticas Telematic Quarantine (2020) y Pandemic Encounter (2020), de Paul Sermon, que telepresentan las historias del aislamiento; y en relación con el concepto «heterotopia», de Michel Foucalt en el contexto del comportamiento en Internet, exploro el trabajo de interpretación en el que he trabajado durante el confinamiento desde marzo de 2020, The Best Facial (2021), con la ayuda del Centro de Investigación de Culturas de Medios Digitales y de la investigación de posgrado de la Escuela de Arte de la Universidad de Brighton. Se trata de una serie de sesiones de 25 minutos de representaciones participativas de telesinestesia de persona a persona en Zoom, en las que me convierto en esteticista virtual y hago uso de la telepresencia para llevar a cabo estrategias faciales virtuales contemplativas, y hacer improvisaciones de telecontacto en la piel del rostro para despertar experiencias táctiles a través de la visualidad háptica, el tacto virtual y la fantasía auditiva.

\section{Palabras clave}

Actuación participativa, visualidad háptica, heterotopia, telecomunicación, sinestesia, fallo técnico 


\section{artnodes}

https://artnodes.uoc.edu

\section{Introduction}

Coming in and out of...

'When so much more can be achieved and saved by reframing our approach to face-to-face coexistence through being creative with our videoconferencing. Making it memorable now could make a difference in the future.' (Sermon, Be creative with your videoconferencing, make it memorable, it makes a difference 2020, n.pag.)

As we are adapting to the effusive after-effects of living through the sudden irregularities teased out by the pandemic, how to extend the face-to-face communication and the shared consciousness at a distance? Our increasing dependence on online interaction during the pandemic is not only facilitating social connectedness, but also contemplating the question: How to elongate our somatosensation along the fiber-optic interface and echo the embodied experience of touching through the incorporeal virtual connectivity?

This essay considers embodied nature of tele-synaesthesia performance as a potential for forging connections between distanced bodies and isolated sensory modalities, and focuses on the situated technological possibilities, such as glitch and internet latency, that mediate non-verbal communication.

In reference to Laura Mark's theory of haptic visuality, where vision triggers a tactile experience in the body; Naomi Bennett's concept of virtual touch, in which an affective sensory response of touch can be elicited through non-tactile senses, Paul Sermon's artistic production of Telematic Quarantine (2020) and Pandemic Encounter (2020), that tele-presents the stories of self isolation, and in relation to Michel Foucault's concept Heterotopia in the context of internet-situated performance, I examine a performance work I developed during lockdown since March 2020: The Best Facial ${ }^{1}$ (2021): a 25-minute 1-to-1 participatory tele-synaesthesia performance that took place on Zoom, where the participants were invited to receive virtual "facial treatment" performed by a fictional character - a virtual aesthetician.

\section{Tele-synaesthesia performance in virtual-real heterotopia}

Tele-synaesthesia performance links tele and synaesthesia to each other. It generates the multiple possibilities of creating synaesthetic effect with people at a distance and people of the future through the transmission of data. Synaesthesia, which means "jointed sensation", which is derived from the Greek word: 'syn', which means together; and 'aisthèsis', which means perception. Synaesthesia means 'the
Making touch visible with the suture of fantasy with virtual aesthetician in glitchy-score of tele-synaesthesia perfor-mance in the age of global pandemic

translation of $[. .$.$] the embodied experiences [...] from one sense$ modality to another' (Marks 2002, ix), and occurs when 'stimulation of one sensory modality automatically triggers a perception in a second modality' (R. E. Cytowic 2002, 2), with the absence of the direct contact or stimulation with the second modality. In this essay, paraphrasing the definition of synaesthesia given by Richard Cytowic in his book Synaesthesia: A Union of Senses (1989), and following the hypothesis of tele-synaesthesia proposed by Dr. Hugo Heyrman in his lecture, 'Tele-Synaesthesia: the Telematic Future of the Senses' (Heyrman 1997), I propose to evaluate the question: how to create a virtual heterotopia to reflect the embodied experience of online communication using the techno-aesthetics of tele-synaesthesia.

According to Foucault, 'places like rest homes, clinics, psychiatric hospitals, and prisons' are the 'heterotopias of deviance', in which 'people whose actions deviate from the norms in some way, and hence need to be spatially isolated' (Foucault 1986). Using the Michel Foucault's concept of heterotopia ${ }^{2}$ (Foucault 1986), I propose to use heterotopia as a conceptual backdrop to frame internet-situated tele-synaesthesia performance space as a virtual-real heterotopia: a deviant space and a virtual-real instantiation of a temporary utopia ideal that carries the potential of maintaining the embodied experiences of distanced bodies and their network of relations during the time of lockdown.

This project uses fiction as a method to create phantasmagorical fantasy of a virtual facial clinic in order to test the threshold of embodied experience in a heterotopic space where the body's the haptic visuality (Marks 2002) and sensuous virtual touching (Bennett 2020) are performed in relation to the distanced participants. Additionally, I propose to identify internet latency and glitch in online communication as open contacts, like surfaces in contact improvisation, that expands the intensity of the embodied experience in internet-situated performances.

In this essay, I will first use the "suture of fantasy" as a metaphor to illustrate how I embrace virtuality and transpose visual tactics in tele-synaesthesia performance. Then, I will trace my reflective practice-based research, along with the presentation, dissemination, documentation, and research feedback from participants, to identify the performative technological anxiety - glitch- as open contact, that triggers non-verbal cues for participation and interaction in internet-situated performances. In the end, I will conclude with my research findings to reflect the embodied nature of internet-situated performance, and to provide a positive affirmation for the symbiotic relationship between the mutability of technological anxiety and the creativity for art practice and research.

1. The selected documentation of the project can be viewed here: https://vimeo.com/563633992

2. According to Foucault, heterotopias refer to "counter-sites" that juxtapose with the unreality of utopias to provide a "curious property of being...to suspect, neutralize, or invert the set of relations' that the reality 'happen to designate, mirror, or reflect'. (Foucault 1986, 3). 


\section{artnodes}

https://artnodes.uoc.edu

\section{The Suture of Fantasy: The First Cut}

'Suture names the relation of the subject to the chain of its discourse; we shall see that it figures there as the element, which is lacking, in the form of a stand-in. For, while there lacking, it is not purely and simply absent.' (Miller 1977)

Suture, as a verb, means to unite, close or secure with sutures ${ }^{3}$. In surgery, a suture is a basic speedy sewing technique that holds together the edges of a cut, a wound, or an incision. A suture performs a viscous action to the cut, while simultaneously immersing what was foreign into the subject itself surreptitiously during the operation. As the wound heals, the suture will eventually become the skin as a part of the body.

In this essay, 'suture'4 is considered as a jump-off point to weave together fantasy and reality in flux: a temporal space for the telesynaesthesia performance to take place, as illustrated in the Figure 1 below. Rather than looking at the 'suture' as a concealer of differences or a closure for the relationships between subjects in the chain of structured discourses, I would like to ask the reader to think of act of suturing as a poetic gesture, that not only reveals the absence of elements that has been lacking as a form of a stand-in, but also creates spaces to situate the tractions and relationships that are generated between different subjects in process of suturing.

When our bodies are confined to a finite space, we should imagine the counter-actualization of the limitation we face by 'transforming negative into positive relations, encounters, and passions' (Braidotti 2011, 31). Echoing Braidotti's nomadic theory that transposes the subjectivity with multiple ecologies of becoming, I created this project

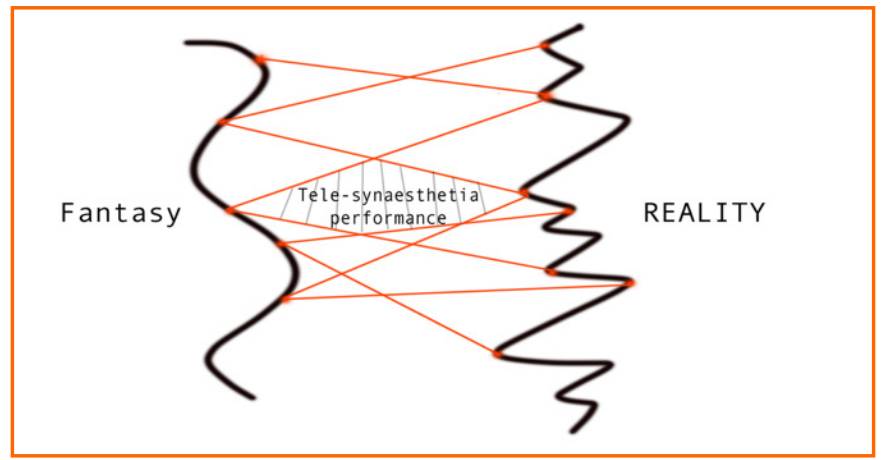

Figure 1. The Suture of Fantasy and Reality, Courtesy of the artist.
Making touch visible with the suture of fantasy with virtual aesthetician in litchy-score of tele-synaesthesia perfor-mance in the age of global pandemic with the aim of transposing the distanced bodies through a nonunitary vision of the digital communication platforms.

During the Covid-19 pandemic, the thought of suturing fantasy and reality allow me to adapt my art practice to blur the virtual embodied experience with its counter-real part. ${ }^{5}$ By cutting off the multifaceted supply of habitual physical contact, there is a higher demand for virtual communication and nostalgia of the past. ${ }^{6}$ The Best Facial was born in such suture. It triggers new sensorimotor gestural channels and perceptual pathways through the spatiotemporal online encounters enabled by videoconferencing tool - Zoom, and virtual corporeal touch envisioned by the use of live audio-visual performance software Resolume Avenue.

Cutting across the spectrum of internet-situated performance, live performance, and digital performance, this project draws two parallel sutures: one connects haptic vision with tactile sensation of touching with virtual-real synaesthesia experiences, the other one draws the link between the tele-synaesthesia performance space and heterotopia. This project addresses the unpresentable void of communication by presenting the conceptual suture that blur our physical and digital presences.

\section{Making touch visible - inhale from the webcam and exhale into the internet as an umbilical cord}

Inspired by Paul Sermon's Pandemic Encounter and Telematic Quarantine (Paul Sermon 2020) (Sermon, Pandemic Encounters 2020), I created an open call to the public to invite participants to join me for a 25-minute 1-to-1 participatory tele-synaesthesia performance that takes place on Zoom, where I become a virtual aesthetician in The Best Facial Clinic. I propose to use The Best Facial project to explore a speculative mode of connectivity and care with a creative use of the videoconferencing tool, while embracing the ambivalence of online communication as a tentative ground.

Building from Maria Puig de la Bellascasa's speculative ethics of care, that is to 'propose modes to contribute to [the] re-articulation, re-conception, and "re-enactment"' (Puig de la Bellacasa 2017, 11) of care, the poster of the open call advertisement (fig. 2.) for participation says: 'The Best Facial: Say Goodbye to Hopelessness'. ${ }^{7}$

3. 'Suture', Merriam-Webster.com Dictionary, Merriam-Webster, https://www.merriam-webster.com/dictionary/suture. Accessed 27 Mar. 2021.

4. 'Suture' is a concept introduced by Jacques-Alain Miller in his essay Suture: Elements of a Logic of the Signifier (Miller 1977).

5. Here, the Covid-19 pandemic has made "the first cut", which cuts face-to-face communication and tactile interaction away from the everyday life.

6. Even though we have already been living in a permanent state of changes before the pandemic, it is still difficult to adapt to the sudden change without being nostalgic about the memories of the past or betting on certain possible future that might take place after the change. Instead of obsessively looking for the differences that are generated by the 'cut' or affirming the changes that have already become overwhelmingly present in our everyday life, as artists, it is urgent now to cope with these challenges of adaptation with the great capacity of the human creativity.

7. The posture of the virtual aesthetician in the advertising poster, along with the slogan at the bottom, is an ironic parody of the society's mainstream notions of care that are commercialized with a high frequency of irresponsible promises and idealized fantasy of beauty. 


\section{artnodes}

https://artnodes.uoc.edu

Making touch visible with the suture of fantasy with virtual aesthetician in "The Best Facial Clinic" - The glitchy-score of tele-synaesthesia perfor-mance in the age of global pandemic

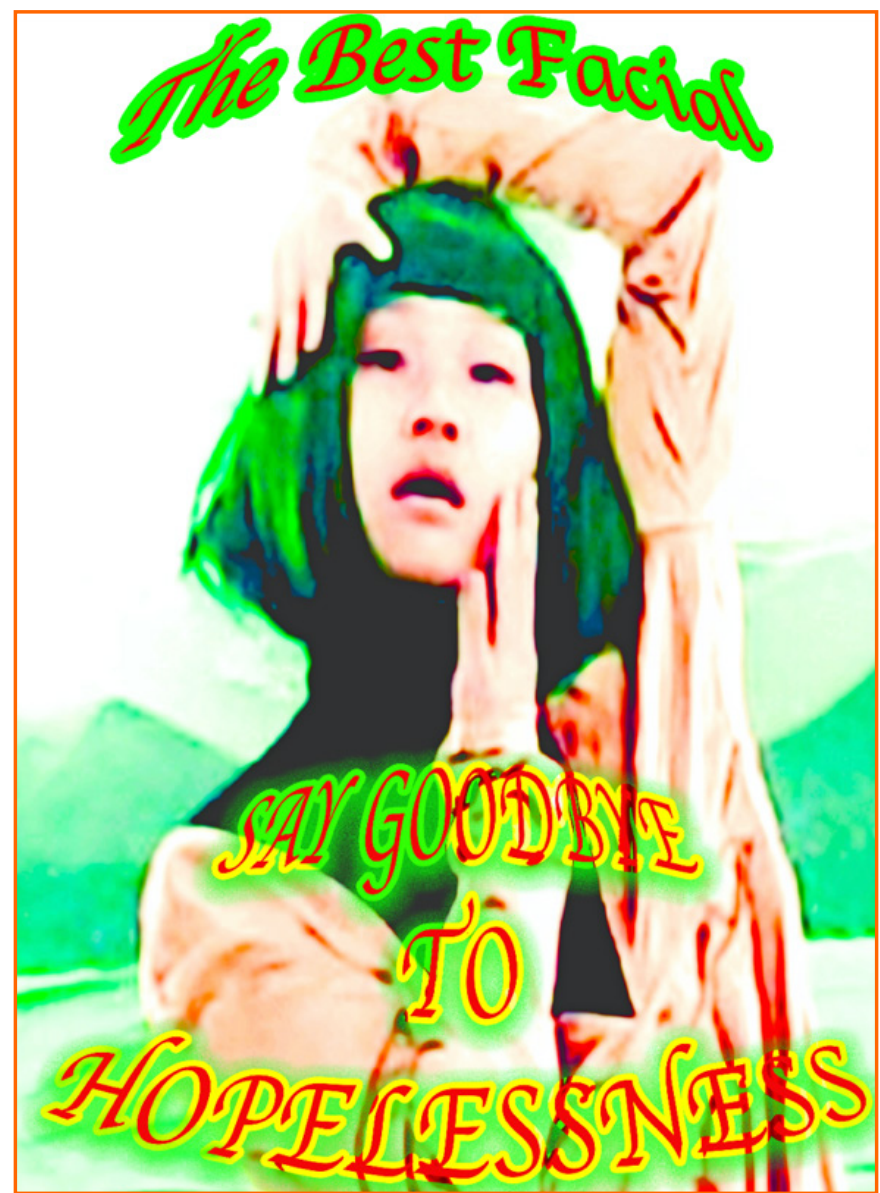

Figure 2. Advertisement Poster for The Best Facial, Courtesy of the artist/writer

Rather than using videoconferencing tool as an alternative of the face-to-face communication, I use fiction as the method to play a role in this virtual fantasy that highlights the sliding relationship between haptic and optical.

How to provoke the experience of being touched by witnessing the gestural touching? How to awake the memory of our tactile sensitivity through synaesthesia, the translation of information from one sensational modality to another? ${ }^{8}$

The gesture of virtual touching is a tele-synaesthesia tactic that fulfils the eye's corporeal cavity with the link drawn between desire and fantasy also connects the physical sensation of being touched and the virtual touching that is witnessed by the participant from

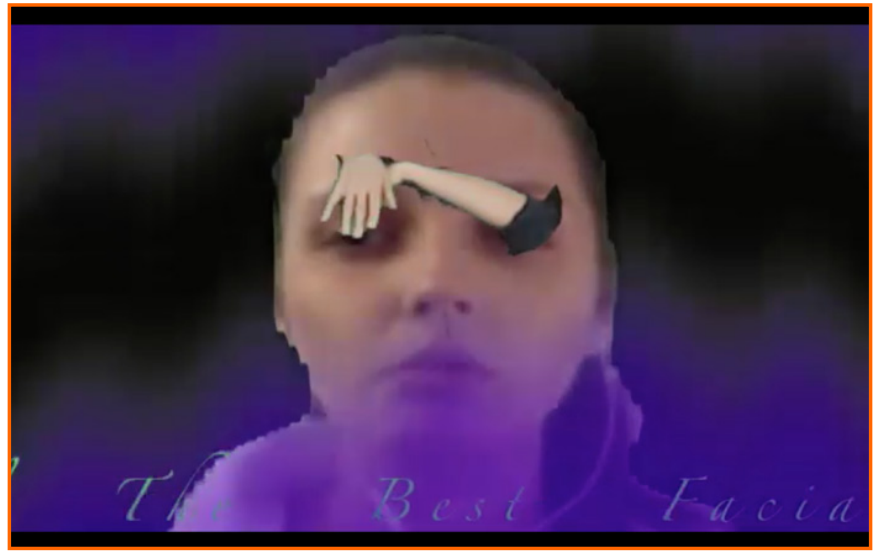

Figure 3. Performance still from The Best Facial, Courtesy of the artist/writer

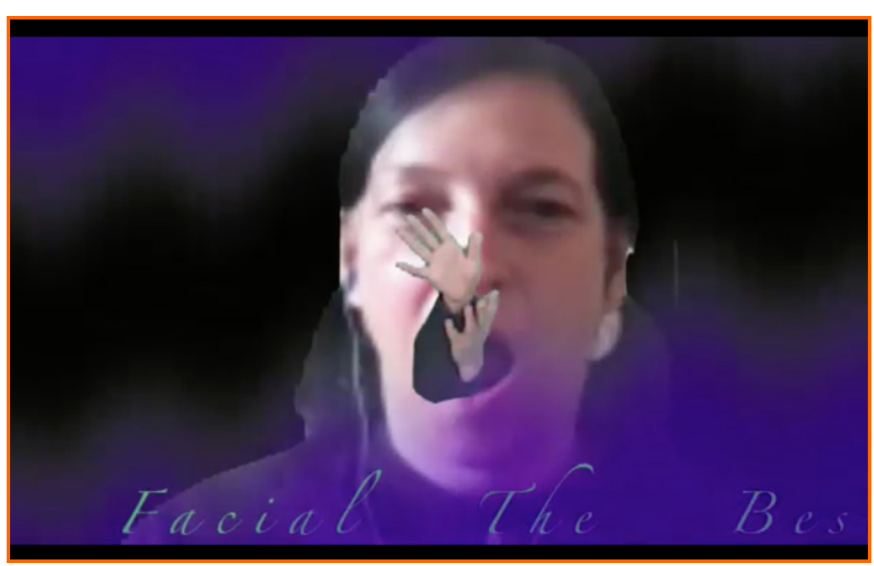

Figure 4. Performance still from The Best Facial, Courtesy of the artist/writer

the computer screen. It could appear to the participant, that they are superimposed into a phantasmagoria when a hand starts to crawl outside of their eyes, mouths and the pores on their faces (fig. 3 \& 4). When participant is witnessing their face being touching, their eyes also initiates an optical contact as a corporeal device.

In the performance, I repeatedly draw connections between touch and surface, touch and contact, contact and screen, the contact with skin and the contract with skin we each have. The contact made by human eyes could be understand as touch that intensifies the sensuous relationship between the screen and the flesh. ${ }^{9}$

One could propose that we have being in contact with or without the physical sensation of being in contact. ${ }^{10}$ In the performance,

8. In the virtual environment, it appears to be difficult to translate all of the information from one physical end to another. As a result, such absence of embodied experience, such as being touched or touch, could be trapped to be revealed through gesture of touch in tele-synaesthesia performance.

9. In relation to what Puig de la Bellacasa writes, 'attention to what it means to touch and to be touched deepens awareness of the embodied character of perception, affect, and thinking' (Puig de la Bellacasa 2017, 96), the contact made by human eyes could be understand as touch that intensifies the sensuous relationship between the screen and the flesh.

10. Here, my proposition for distant touching echoes with Cytowic's conceptualisation of synaesthesia: 'while sensing emotions concretely as particular colours, shapes, or tastes can lead to intensely felt experiences, it can also facilitate identifying those feelings and resolving conflicts within oneself and with others.' (R. E. Cytowic 2018) 


\section{artnodes}

https://artnodes.uoc.edu

Making touch visible with the suture of fantasy with virtual aesthetician in

"The Best Facial Clinic" - The glitchy-score of tele-synaesthesia perfor-mance in the age of global pandemic

I blur relationship between optic and haptic by engaging with the distant vision that provides alternative ways for the participants to feel being touched. ${ }^{11}$
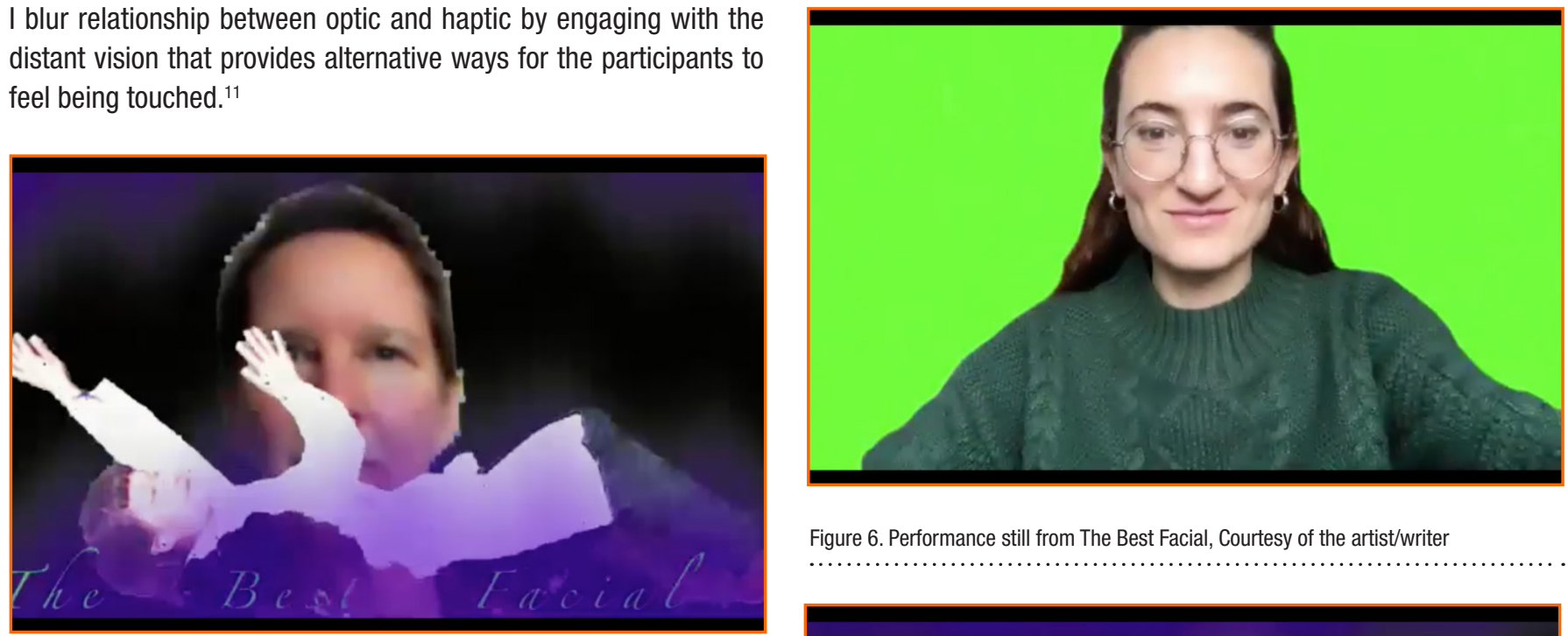

Figure 6. Performance still from The Best Facial, Courtesy of the artist/writer

Figure 5. Performance still from The Best Facial, Courtesy of the artist/writer

Prior to the virtual facial session, the participants are asked to fill an online assessment form ${ }^{12}$ to resemble the facial service that is provided by commercial beauty parlour and build up the sense of suspense and expectation for the participant. This pre-session assessment form also allows me to make the first "contact point" with the participant without any knowledge about who they are, but with enough information to design a "treatment plan" for the virtual facial session with the participant.

The "treatment plan" is a composed of choreographed audio soundtrack and improvised actions. During the session, I virtually superimpose the participant's face into the virtual background of The Best Facial Clinic, in which is presented with animated purple waves against a black background and an ongoing subtitle that says, 'The Best Facial' by the bottom of the screen, using virtual camera output, Camtwist and live VJ software Resolume Avenue, as shown in fig.6. \& 7. Then, I start to play the pre-recorded narration about touch with a meditative soundtrack that is composed digitally, so

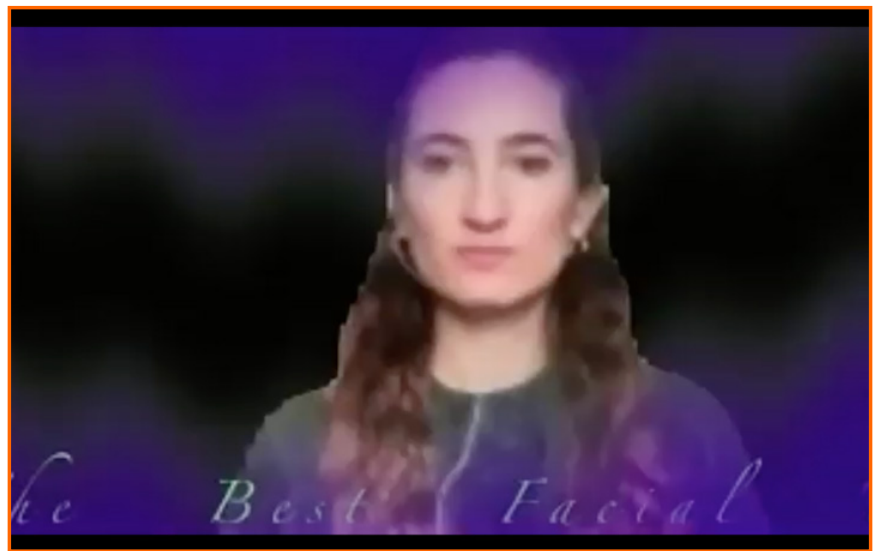

Figure 7. Performance still from The Best Facial, Courtesy of the artist/writer

to cultivate an atmospherically vacant and peaceful environment, where the participant could be teleported into a different space than their own home.

The soundtrack ${ }^{13}$ is an essential element in this tele-synaesthesia performance. ${ }^{14}$ It functions as the score for the performance and guides the participant to use the auditory sensation to further trigger the possible haptic sensation with the distant vision. ${ }^{15}$

11. To start the session (fig. 5), I would guide the participant to start a short breathing exercise, by asking them to breath in from their nose, and breath out through the mouth. Followed by a synaesthesia game to imagine the web camera as a breath chamber that provides air, that is passed through the umbilical cord of the fibreoptic internet cable, which allows me to start the virtual connection with them.

12. The pre-session assessment can be viewed through this link: https://docs.google.com/forms/d/1nbnFOY6IIPgr968QyFr_kYsc1u2s8VxHfDZKRxo3PsA/ viewform?edit_requested=true

13. As the soundtrack is playing, I use Resolume Avenue to playfully apply different transformations using the built-in function of the software, such as scale of the participant's face (fig.8), the closeness between the face and the frame of the screen, the position of the face on the screen (fig.9), and the level of transparency of the participant face. The action of these playful transformations is synced live with the soundtrack, as I drag the computer mouse adjust the level of intensity for each transformation.

14. The full version of the soundtrack can be read here: https://drive.google.com/file/d/1QP7LAxh0Q_im3iWYlveqnBTkTOc4261q/view?usp=sharing; The full version of the soundtrack can be listened to here: https://drive.google.com/file/d/1-5PV_kcdXzpNiE6wIW6ovwZ91yqn9Kc8/view?usp=sharing

15. The participant is encountered with the contextual emplacement first with the sentence, 'you are always in contact', which is repeated in the beginning of the first act of the soundtrack in four segments. 


\section{artnodes}

https://artnodes.uoc.edu
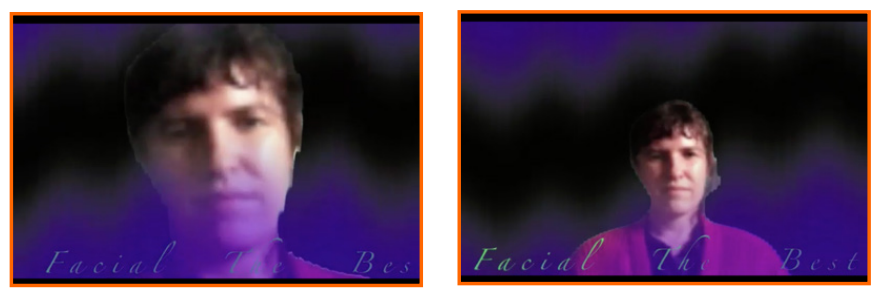

Figure 8. Performance still from The Best Facial, Courtesy of the artist/writer
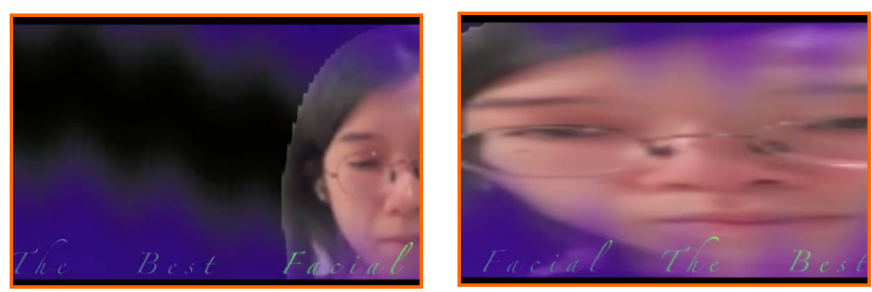

Figure 9. Performance still from The Best Facial, Courtesy of the artist/writer

The first segment of act 1 in the performance is focused on the peripheral vision and subjective perspective of the participants in relation to the surfaces that their bodies are in contact with. ${ }^{16}$

In segment two to four, of approximately 5 minutes, I focus on the visceral awareness of the fragmented body parts. ${ }^{17}$ During these three segments, I start to play with the scale and position of the participant's face, in order to accentuate on the relationship between the participant's physical spatial awareness of their face and the visual spectacle of their face. At the same time, I use the chroma-key function in Resolume Avenue and substitute the participant's facial surface with found films, pre-recorded moving image and recordings of the natural landscape, as shown in fig. 11 \& 12 .

You are the contact, you are the surface, you are the interface, you are becoming the contact with yourself by becoming yourself. You have become the contact that reveal what, who, where and how you are in contact with.

(Selected text from Act 2 of the soundtrack)

In the second act of the performance, I then leave the participant wait in the clinic for the second time, in order to allow time for the participant to perceive what has happened in the last 5 minutes. ${ }^{18}$

Where is your skin? Isn't it amazing that you are held in contract with your skin without the need to balance the tension between each of
Making touch visible with the suture of fantasy with virtual aesthetician in

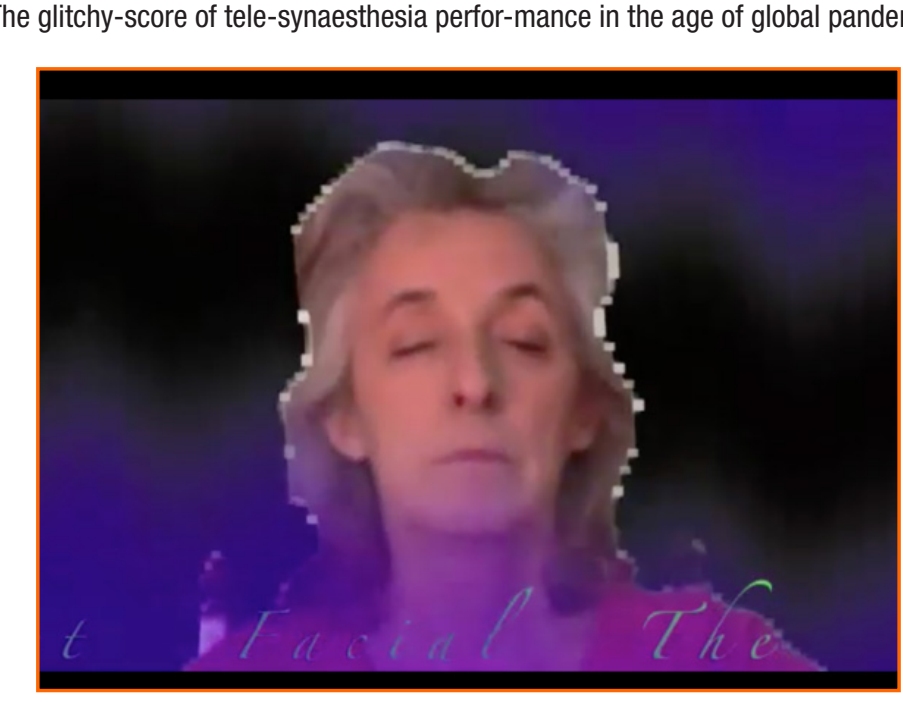

Figure 10. Performance still from The Best Facial, Courtesy of the artist/writer
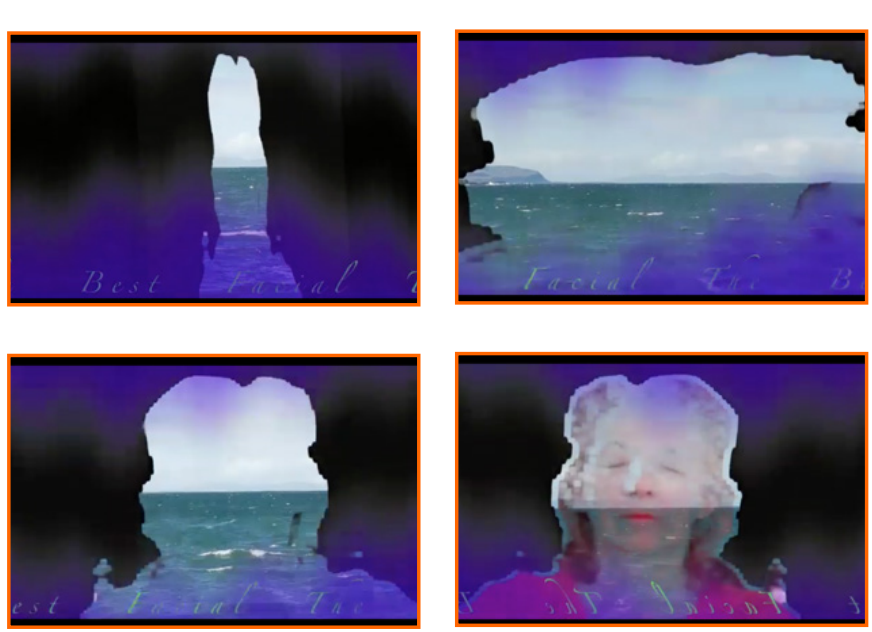

Figure 11. Performance still from The Best Facial, Courtesy of the artist/writer
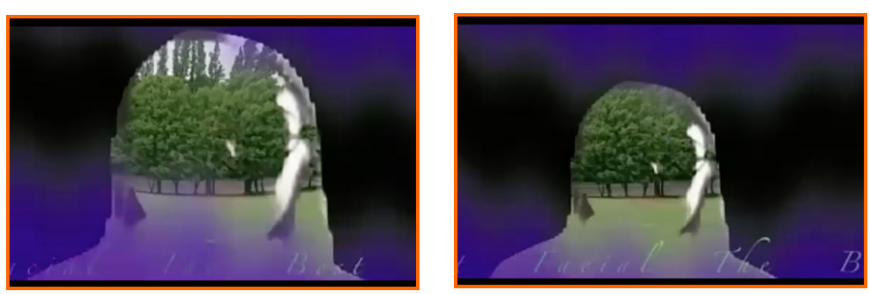

Figure 12. Performance still from The Best Facial, Courtesy of the artist/writer

16. During this segment, I leave the participant in "The Best Facial Clinic", so that the participant could continue with the beginning breathing exercise and to be comfortable with the spectacle of their own face superimposed in the virtual background, shown in fig 10.

17. To activate the participants' self- consciousness and self-awareness of the physical body, I annunciate the less-attended parts of the body, such as the roof of the mouth, fingertips, scalp, teeth, togue, lips, hair, nails; then I bring the relational awareness of the body in reference to the other bodies in the everyday life, such as neighbour, strangers encountered on the street, mailman, lover, friends and people who extend the sensible dimension of the self; and then I construct speculative contacts that could provoke memory of the body in a domestic environment, such as household appliances, old clothes, abandoned things, things one have touched once before, and things forgotten and left in the corner of the room.

18. In the performance, the scale of the participant's face was enlarged to increase the surface area of experience. 


\section{artnodes}

https://artnodes.uoc.edu

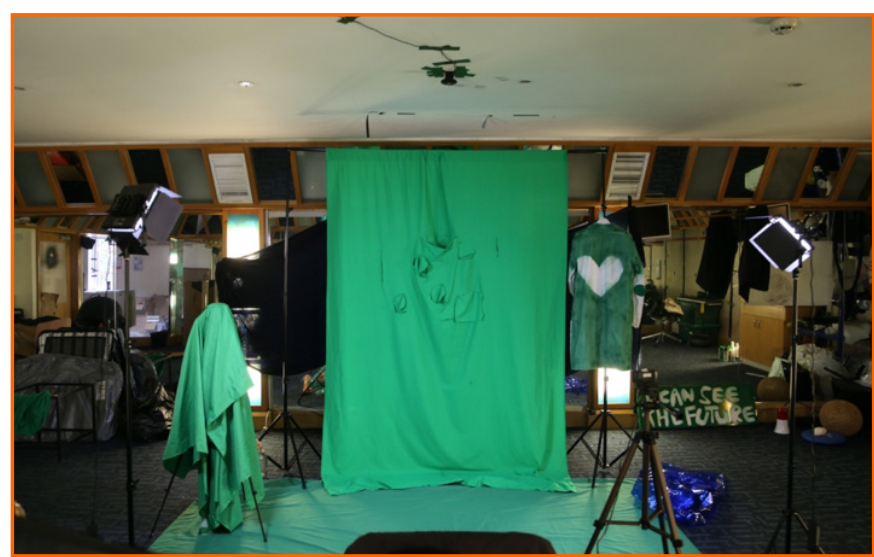

Figure 13. Studio installation of The Best Facial performance set-up, Courtesy of the artist/ writer
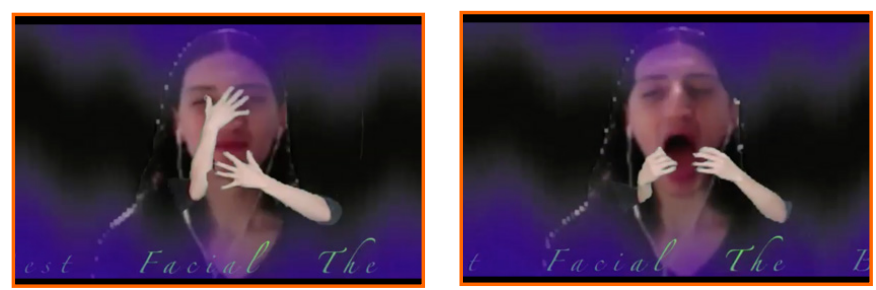

Figure 14. Performance still from The Best Facial, Courtesy of the artist/writer

the organs in your body? Isn't it amazing that you are able to feel what's outside without ripping your skin open? Isn't it amazing that you can see what is outside while being inside of the skin? (Selected text from Act 3 of the soundtrack)

In the third act of the performance, I then start to virtually superimpose my hands, arms and my body inside of the virtual clinic..$^{19}$ During this act, I first use the front camera that captures the greenscreen hanging up. I start to play with the visual tropes of superposition and surrealistic imagery using my hands and arm in order to trigger tactile sensation. ${ }^{20}$ According to the feedback of the participants, some of them could actually feel a tingling sensation when my hands were tapping their forehead and eyebrow. This is one of the most effective synaesthesia experiences that the participant could be able to describe and locate.
Making touch visible with the suture of fantasy with virtual aesthetician in -score of tele-synaesthesia perfor-mance in the age of global pandemic

I will now introduce a friend, a slug. It will move across your face to take away the dead skin cells that have become alien to your face. It's leaving a wet trail as it's moving slowing around your face, with a path left behind. You face is now all moisturized, all fresh, all flesh, all anew, like a new born.

(Selected text from Act 4 of the Soundtrack)

In the last act of the performance, I use the web camera that is installed on the ceiling of the studio in order to emplace my entire body into the participant's face to perform the last set of virtual facial treatment. ${ }^{21}$
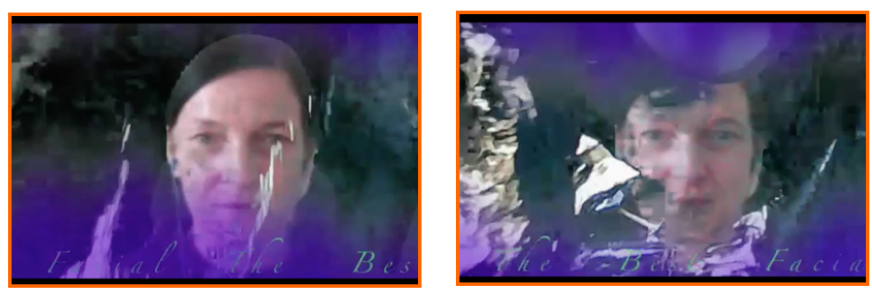

Figure 15. Performance still from The Best Facial, Courtesy of the artist/writer

Toward the ending of the performance, I would use my own body as a "ruler" to align the participant's face in relation to my physical body lying on top of the greenscreen on the studio floor, as shown in fig. $16 .{ }^{22}$
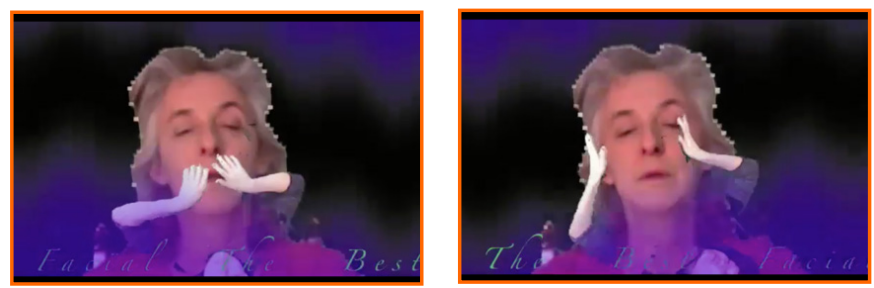

Figure 16. Performance still from The Best Facial, Courtesy of the artist/writer

The proprioceptive choreography of body movements, facial expressions and hand gestures are key components to any conversation, often used unconsciously, but by simply combing these views within the same image we become kinaesthetically conscious and in control of our combined coexistence, escaping our individual isolation.

19. Practically, I use two web cameras, with one installed on the ceiling of the studio, and another one positioned in front of the green screen. As shown in fig.13, the web camera installed on the tripod by the lower right corner of the photograph is the front camera. The web camera that is taped to the ceiling by the top of the photograph is the other image capture device I use.

20. For example, I slowly stroke the eyebrows of the participant when the soundtrack says, 'Can you feel your eyebrow? Try to move your eyebrow to scale the size your face'. Or, I would gradually stick my arms outside of the participant's mouth, when the soundtrack says, 'take another deep breath you're your mouth open wider. When the breath is out, let your breath penetrate what you see', as shown in fig.14.

21. For example, I would wrinkle a transparent blue plastic sheet in front of the web camera, when the soundtrack says, 'I will now introduce a friend, a slug. It will move across your face to take away the dead skin cells that have become alien to your face', as shown in fig.15.

22. This is what I refer to as virtual contact improvisation. Because I was touching my own body, while it appears to the participant that I was touching their face. According to the participant's feedback, this section invokes the most effective sensation of touch, because of the accuracy of the virtual touch. 


\section{artnodes}

https://artnodes.uoc.edu
Making touch visible with the suture of fantasy with virtual aesthetician in "The Best Facial Clinic" - The glitchy-score of tele-synaesthesia perfor-mance in the age of global pandemic

\section{Glitch as a non-performative refusal - Embracing the change in the suture of fantasy}

In the performance, I re-membered glitch into the process of creating internet-situated tele-synaesthesia performance, by addressing glitch as a digital mutation, in parallel to the organic mutality of Coronavirus - that simultaneously performs the "unsanitary error": the technological anxiety that is independent from the human will, and calls out for a 'non-performative' action.

In the beginning of the lockdown in March, 2020, I was overwhelmed by the over-saturation of the glorification of using internet as a medium to disseminate artworks. ${ }^{23}$ However, it has occurred to me that, it is more urgent than ever to stop comparing the differences between face-to-face and internet-situated communication, but to create symbiotically with technology as more than a mediator or a one-way output-orientated machine.

Instead of working on ways to overcome the technical imperfection of internet-situated communication, I started to pay more attention to the messiness and failures activated by the use of internet and internet-based software. ${ }^{24}$ Going along with the feedback loops between the artists and audiences and between the artists' creation and individual's need to self-identify and self-actualize, the increasing demand for internet-situated performances and artworks, especially during the time of the pandemic.

Such demand also creates an archive for the contemporary art and performance practice, while cultivating a historical background for the future development and innovation of internet-situated performance. Hence, it is crucial to diversify the practice of internetsituated performance. In order to do that, I would like to focus on the understanding of glitch, as a correlated feature and an often forgotten characteristic of internet-situated performance.

A glitch is an error. It is invisible until it is visible. A glitch can be accidentally triggered, yet the appearance of glitch cannot be predicted. The power of a glitch could cut the continuous happening that connect our perception of time and space. When we experience glitch in online communication, words become fragmented, and images start to embody an involuntary instability that disrupts the integrity of our perception and re-contextualize our vision in a different time and space.

Each glitch is unique, as described in Glitch Feminism: A Manifesto, by Legacy Russel: 'errors bring new movement into static space; this motion makes an error difficult to see but its interference ever present'. (Russell 2020) In order to identify the glitches, I identify glitches not as errors, but as open points of contacts that creates spaces that fore-ground potential interaction with the participant.

I purposefully chose to use the low-resolution output to increase the duration and frequency of glitch..$^{25}$ Using the nostalgic affect of low-resolution related to early days of internet, the glitches triggered by internet latency or CPU overload during the performance would not only introduce new movement into the 'static space', but also make the interference of glitches into organic ephemeral changes that are organic to tele-synaesthesia performance. These ephemeral changes are the metaphorical contact points, for which become a virtual interface for performative interactions, actions and reactions.

Hence, I use digital improvisation in The Best Facial project to create more possible "glitches" in addition to the existing glitches and the ephemeral changes, as shown in fig. 17. During the performance, the participants and the technological beings I work with both undergo the process of 'having technical ensemble and becoming reabsorbed in a new technical [and virtual] ensemble, performing a similar or different function there' (Halyes 2012, 103) I would ask questions, such as, did you feel me touching you during the performance, and which action give you the most effective feeling in relation to touch and being touched.
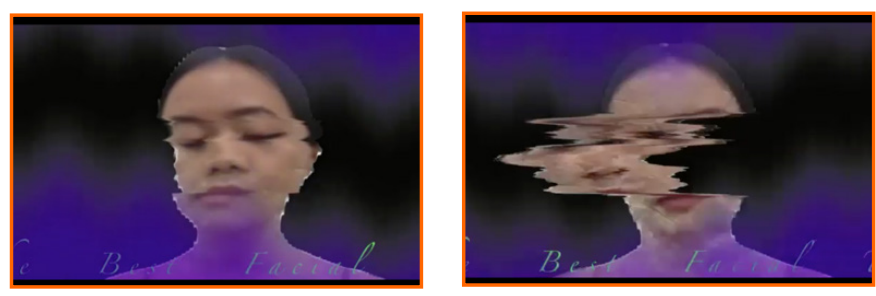

Figure 17. Performance still from The Best Facial, Courtesy of the artist/writer

Aesthetically, the "clumsiness" of the tech worked really well with the absurdity of the interaction (even if the initial glitching was quite maddening). I was very curious to see how Ada would re-imagine haptic interaction across the virtual divide and was gratified to experience her wonderfully barmy and playful approach to this challenge. (Selected response from participant's post-performance feedback)

...When Ada moved her 'hands' along the hairline on my forehead in longer movements I could 'feel' that - days later I still can. As the session progressed I went from trying to keep my head still

23. Such as using different social media platform to publish and share documentation of live performances, virtual gallery tour, representation of live theatrical production; or online Zoom panel discussions that ends with how to get over "Zoom fatigue" that leads to tiredness and physical exhaustion.

24. However, I do not want to dismiss the increasing quantity of performances that use the internet as a medium to disseminate work. As a survival mechanism, digital media is imbued with 'fantasy today is not a retro act of mythologizing' (Russell 2020)

25. I also embrace the limit performance capacity of my performance hardware to allow a continuous feed of glitches, such as face or body freezes, stuttered or unclear communication, low frequency buzzing in the soundtrack's background, and sudden disappearances of imagery or disconnection during the course of online performance platform. 


\section{artnodes}

https://artnodes.uoc.edu

to moving my head as a way of interesting with the imagery and Ada's 'touch' - whilst that didn't lead to any tactile sensation it did make my experience feel more generally embodied and engaged. (Selected response from participant's post-performance feedback)

Rather than thinking of create an artwork that is only responding to the temporal changes, as Boris Groys proposed: 'how can artists resist the destructiveness of progress? How can one make art that would escape permanent change-art that would be atemporal, transhistorical?' (Groys 2010) ${ }^{26}$

Within these virtual-real heterotopias, the virtual embodied experience of the body could be remembered, displaced and composed differently despite not being altered, changed or moved in its physical presence. If we think virtual-real heterotopias as if they are experiments in scientific lab, where the body would appear to be transformed for the viewer's eye and mind, like phenomenon scientists could observe in a practical experiment in the lab, the reaction or metamorphosis of the body would only happen with the visual spectacle, instead of the actual body. Is that so? I disagree. Like the phantom limb pain, tele-synaesthesia performance could activate such virtual-real heterotopias, where one would embody the vision, feel the image, and even become tempted to react to such invisible sources of sensorimotor activation.

Tele-synaesthesia performance does not necessarily offer a solution to cope with limitation imposed by the physical distance for human-technology and human-human communication, but to propose a question that artists could ask themselves: What is the creative use of the technological uncertainty and the embodiment of the precariousness in the society? How to become present in relation to the advancement virtual spaces and digital developments? Why do we use work with technology and internet in the first place?

\section{Conclusion}

Tele-synaesthesia performance could be a novel performance art practice that transposes differences between individuals into opencontacts that make the most use of online communication. Instead of only using online communication as a platform for presentation, this essay stress the awareness of the mutability of glitch in internetsituated performance and its potential to activate new sensorimotor through the techno-aesthetics that re-cartograph the embodied experience in a globalised network culture, without 'upholding the unity of space and time as its governing principle'. (Terranova 2004)
Making touch visible with the suture of fantasy with virtual aesthetician in

My intension of creating this internet-situated performance is to substitute the practice of live performances we witness in person. My attempt of discovering creative use of online communication tool is to perform, reflect and archive my share of the collective experiences of living through the global crisis in the age of the tactical new media.

When I ask participants what their faces feel like, $66.7 \%$ of the participants felt that their face has become a playground, with an equal percentage of the rest of participants saying that their faces has become a void or a new speculative that they can't name. This data shows that tele-synaesthesia performance is such playground, which creates potential embodied experience that sutures the fantasy together with reality for participants. In relation to Foucault's proposition of heterotopia as deviant spaces in the reality, internet-situated performance creates such 'heterotopias of deviance', that provides a virtual playground that invites spatially isolated bodies to perform durational deviancy.
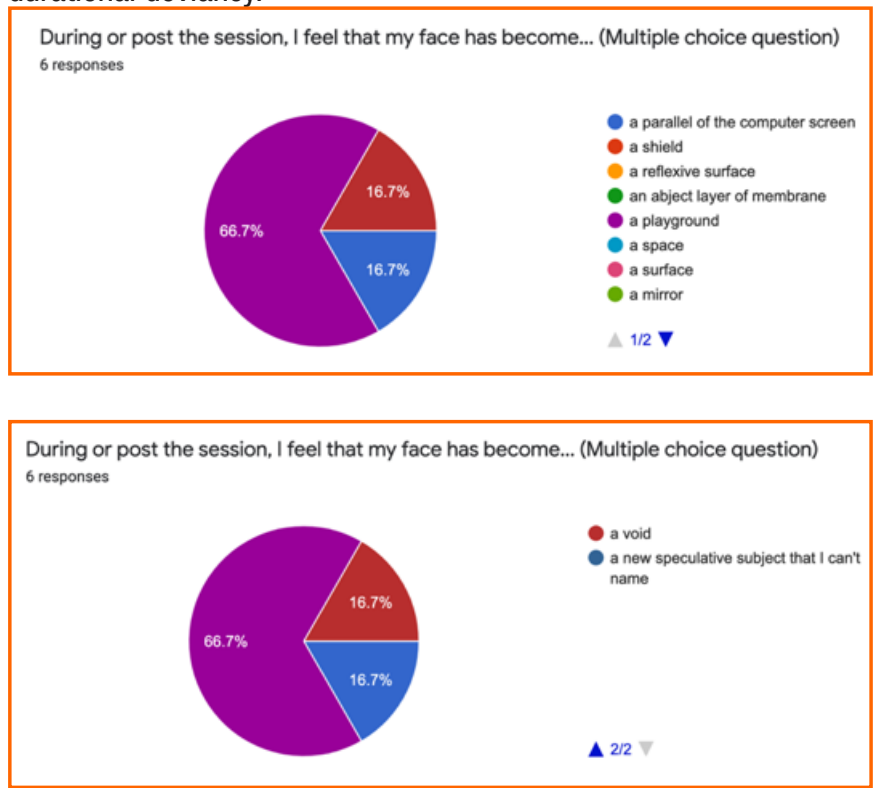

Figure 18, Participants' feedback form generated by the questionare using Google Form, Courtesy of the art-ist/writer

In addition to Foucault's conception of heterotopia, heterotopia also refers to the displacement of a part of the body from its normal position in the context of medicine. The playful connections and intersections between body and space the internet-situated performances that I discussed in this essay, like Stelarc's implantation of a third ear on his own arm, have enabled the performing bodies to virtually be in contact with each other in different precarious

26. I agree that change should be the status quo, and 'permanent change is our only reality... to change the status quo would be to change the change- - to escape the change... every utopia is nothing other than an escape from this change' (Groys 2010), and hence every virtual-real heterotopia could be a multiple temporary traps to reveal and archive what has or has not escaped from such change. 


\section{artnodes}

https://artnodes.uoc.edu
Making touch visible with the suture of fantasy with virtual aesthetician in "The Best Facial Clinic" - The glitchy-score of tele-synaesthesia perfor-mance in the age of global pandemic spaces of time, while bearing the spatial existence and movement of each other virtually.

When the physical reciprocal contact is absent, the eye become an organ that takes on a tactile functionality. Is touch visible? Could you feel me touching you with your eyes? When the continuity and normality of the common everyday places are disrupted, how do we recontextualize our relationships with each other? Based on Marks's theory of haptic visuality, that uses visual sensation to create tactile response in the body (Marks 2002), and Bennett's virtual touch, that embodies a visceral experience with the feelings of touch to be elicited through the visual senses, 'transcending the presence of physical contact' (Bennett 2020), these internet-situated performances have constructed a model of creating virtual-real-heterotopic spaces, where virtual touching could become the reciprocal sensor receptors that feed into the playful interaction between the performer, the action-performers, and the participants.

The Best Facial operates as a 'heterotopia of deviance', that gestures toward the 'fissure within which new possibilities of being and becoming manifest' (Russell 2020, 11) ${ }^{27}$, and emplaces the delayed feedback without inserting a compulsory etiquette that asks for immediate reaction or interaction from the participant.

This new preceptive displacement of the way we interact with each other has shifted from the pre-Covid-19 times and emplaced our perception toward change with a new perspective. The virtual displacement of our body could potentially change our habitual way of interacting with each other post-Covid-19 pandemic. Because the focus of this change is not necessarily lying at the core of what has changed, but invoking questions such as: How do we adapt to the change? How to access our vulnerability and incapability during the time of change? How to use the mutability of technology as a contact point to extend the embodied experience in the temporarily encapsulated space and time? Could there be more virtual-real heterotopias out there?

These questions about change function as guiding navigational tools to allow us to tell the difference between different flow of change and mutation, in particular the reactive changes made out of fear and the affirmative empowerment of alternative embodied experiences we could create and develop in the process of changing.

Like getting a facial treatment in beauty clinics, this performance is a creative resource of imagination that constantly renews the sense-making process for the subject self. The slogan 'Say Goodbye to Hopelessness' ironically creates a false hope, which negates the assumption that we could forget about what happened in the past and get back to "normal" way of living, especially to a life postpandemic. The Best Facial not only exposes a new virtual territory for performative interventions that attempt to negotiate a reciprocal relationship between techno-aesthetic and embodied experience of participation, but also creates a spatio-temporal virtual healing scenario to allow individuals to experience the frictions of adapting to change and to transpose the feeling of lonliness and hopeless into individual's structural ability to actualize oneself as a process of transformation. Even though it is urgent to think of online communication not only as a medium to disseminate the network of relations or a technology for human-computer interaction, but also a material-based practice that posits a code of conduct, which could be disrupted, interrogated and dismantled for the purpose of making the most complete use of its potential for personal expression. It is more urgent that ever to create a sustainable practice of care that initiates interconnections among individuals that are not bound by the consumptive nature of online communication and the nostalgic desire for "normal" socialization that resorts into human-human interaction only.

The embodied nature of internet-situated performance, as discussed in the essay, should be placed at the very heart of online communication to "suture" together the imaginable and the possible. The very reason that I consider internet-situated performance heterotopic is a reflection of the absence of deviant spaces in our society. If the pandemic is a spatial-temporal phenomenon that demands a remapping of our social interactivity, we should consider this change of pace as a catalyst to find new coordinates and scores for online communication, such as glitch and internet latency, to sustain the symbiotic relationship between the mutability of technological anxiety and the creativity in art practice and research.

\section{References}

(SAGE), Scientific Advisory Group for Emergencies. 2020. "SPI-B:Wellbeing and Household Connection: the behavioural considerations of 'Bubbles'." GOV.UK. June 12. Accessed March 21, 2021. https:// assets.publishing.service.gov.uk/government/uploads/system/ uploads/attachment_data/file/892048/S0356_SPI-B_Wellbeing_and_Household_Connection.pdf.

Bennett, Naomi Petrea. 2020. "Virtual Touch: Embodied Experiences of (dis)Embodied Intimacy in Mediatized Performance." LSU Digital Commons. May. Accessed March 22, 2021. https://digitalcommons. Isu.edu/gradschool_dissertations/5225.

Braidotti, Rosi. 2011. Nomadic Theory: The Portable Rosi Braidotti. New York: Columbia University Press.

Cytowic, Richard E. 2018. Synesthesia/ Richard E. Cytowic, M.D. Cambridge, MA: MIT Press. DOI:https://doi.org/10.7551/mitpress/10568.001.0001

27. It also resembles the pandemic and delivers a message that we could walk out of them with hope for the unforeseen future. It is important to know that we could live through the pandemic and continue living without retreating to the sheltered position. 


\section{artnodes}

https://artnodes.uoc.edu

Making touch visible with the suture of fantasy with virtual aesthetician in "The Best Facial Clinic" - The glitchy-score of tele-synaesthesia perfor-mance in the age of global pandemic

Cytowic, Richard E. 2002. Synaesthesia: A Union of the Senses. Cambridge, Massachusetts: The MIT Press. D0l: https://doi. org/10.7551/mitpress/6590.001.0001

Foucault, Michel. 1986. "Des Espace Autres (Of Other Spaces: Utopias and Heterotopias)." October: 1-9.

Groys, Boris. 2010. "The Weak Universalism." e-flux (15).

Halyes, N. Katherine. 2012. How we think: digital media and contemporary technogenesis. Chicago and London: The University of Chicago Press. DOl: https://doi.org/10.7208/chicago/9780226321370.001.0001

Heyrman, Dr. Hugo. 1997. "doctorhugo.org." July. Accessed March 22, 2021. http://www.doctorhugo.org/synaesthesia/e-tsyn.htm\#: :t ext=Tele\%2Dsynaesthesia\%3A\%20virtual\%20interactions\%20 between,constraints\%20of\%20the $\% 20$ human $\% 20$ senses.

Marks, Laura U. 2002. Touch: sensuous theory and multisensory media. Minnesota, MN: University of Minnesota press.

Mental Health Foundation. 2021. "One year of covid: Ioss and gain." mentalhealth.org.uk. February 25. Accessed March 21, 2021. https://www.mentalhealth.org.uk/coronavirus/one-year-covidloss-and-gain.
Miller, Jacques-Alain. 1977. "Dossier Suture: Suture (elements of the logic of the signifier)." Screen 18 (4): 24-34. DOl: https://doi. org/10.1093/screen/18.4.24

Paul Sermon, Randall Packer, Gregory Kuhn. 2020. Pandemic Encounters: BE-ING[TOGETHER] IN THE DEEP THIRD SPACE. May 23. Accessed March 28, 2021. https://research.brighton.ac.uk/en/ publications/pandemic-encounters-beingtogether-in-the-deepthird-space.

Puig de la Bellacasa, María. 2017. Matters of care: speculative ethics in more than human worlds. Minneapolis, Minnesota: University of Minnesota Press.

Russell, Legacy. 2020. Glitch Feminism: A Manifesto. London, NY: Verso.

Sermon, Paul. 2020. Be creative with your videoconferencing, make it memorable, it makes a difference. 21 April. Accessed March 20, 2021. https://blogs.brighton.ac.uk/creative/2020/04/21/ be-creative-with-your-videoconferencing-make-it-memorableit-makes-a-difference/.

Sermon, Paul. 2020. Pandemic Encounters. May 23. Accessed March 27, 2021. http://paulsermon.org/pandemic-encounters/.

Terranova, Tiziana. 2004. Network culture: politics for the information age. London: Pluto Press. 


\section{artnodes}

https://artnodes.uoc.edu

Making touch visible with the suture of fantasy with virtual aesthetician in "The Best Facial Clinic" - The glitchy-score of tele-synaesthesia perfor-mance in the age of global pandemic

\section{CV}

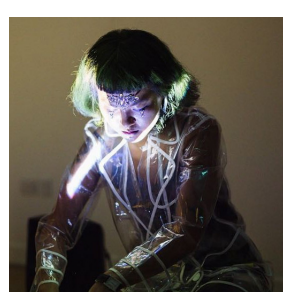

\section{Ada Xiaoyu Hao}

University of Brighton

oahada@gmail.com

Current PhD Projects: https://aproductionofmultiplebecomingsofsubjectivities.cargo.site/Desktop

Artist website: https://www.adahao.org/

Performance Artist Researcher

Born in China. Currently live and work in London, UK

I'm an artist-researcher, born in China and currently doing a practicebased Ph.D. in the Doctoral School of Art \& Communication, at University of Brighton. My practice is situated within performance practice, using role-playing and fiction as methods to trigger and explore the emergences of spatial-temporal 'heterotopias' (spatial otherness), in relation to the futurity of human beings under the veil of "becoming multiple". I'm interested in exploring ways to renew individual subjectivity and to embody a speculative envisaging of what the human body could be or become. During such diffractive process of becoming, the performance space becomes a virtual site where social attitudes and cultural identities are negotiable. My recent research output includes a digital peer-reviewed visual essay for The International Journal of Creative Media Research's Digital Ecologies: Fiction Machines (Issue 5), digital collaboration with British Art Studies' Issue 13, and a peer-reviewed article for the Journal of Contemporary Chinese Art 2021's Special Issue: 'The World, Two Meters Away'. 